\title{
Rainfall variability analysis using Precipitation Concentration Index: a case study of the western agro-climatic zone of Punjab, India
}

\author{
Kishan Singh Rawat ${ }^{1}$, Raj Kumar Pal ${ }^{2}$ and Sudhir Kumar Singh ${ }^{3}$ \\ Geo-Informatics, Civil Engineering Department, Graphic Era (Deemed to be University), Dehradun - 248002, Uttrakhand, \\ India ${ }^{1 *}$, Punjab Agricultural University, Regional Research Station, Bathinda, Punjab, India ${ }^{2}$, and K. Banerjee Centre of \\ Atmospheric \&amp; Ocean Studies, IIDS, Nehru Science Centre, University of Allahabad, Prayagraj-211002 (U.P.), India ${ }^{3}$
}

Received: 2021-04-27

Accepted: 2021-11-16

Keywords:

Agro-climatic zone;

Climate Changes;

Precipitation Concentration Index; Variability;

Wet and dry season

Correspondent email:

ksr.kishan@gmail.com

\begin{abstract}
Due to climate change, the rainfall pattern has changed, which ultimately either cause flood or drought in any region of the world. Hence, a rainfall variability analysis helps to manage the water resources better. Rainfall variability analysis of a long term at particular area reveals vital information about past and future climate. The study's objective was to analyse the rainfall variability and intensity of long term monthly rainfall data (1982-2018) using the Precipitation Concentration Index (PCI). Data was collected from Punjab Agricultural University, Regional Research Station, located at Bathinda, India. The PCI was calculated for the annual, winter, pre-monsoon, monsoon, post-monsoon season, and decadal scale. Results have outlined that $\mathrm{PCI}_{\text {Annual }}$ ranges from the lowest of 14.96 in 2006 to the highest of 43.82 in 2000, and the average of 37 years is 23.22. About $\approx 59.5 \%$ of the year $\mathrm{PCI}_{\text {Annual }}$ was characterised by Strong Irregularity of Precipitation Distribution (SIPD, $\mathrm{PCI}_{\text {Annual }}>20$ ), an indication of SIPD within the 37 years. While $\approx 2.7 \%$ of the year recorded annual value within the moderate irregular range $\left(10<\mathrm{PCI}_{\text {Anuual }}<15\right)$, which indicates an irregular rainfall distribution (MIPD) and concentration across the months. Similarly, the precipitation concentration in China was also found strongly irregular in the western and northern parts of the northwest and the northern region of the Tibetan Plateau. The study recommends that the Bathinda Development Authority (BDA) may use and adopt these results and redevelop the existing groundwater recharge structures (pond) and artificial recharge structures.
\end{abstract}

Q2021 by the authors. Licensee Indonesian Journal of Geography, Indonesi

This article is an open access article distributed under the terms and conditions of the Creative Commons Attribution(CC BY NC) licensehttps://creativecommons.org/licenses/by-nc/4.0/.

\section{Introduction}

The availability of water resources of any region depends on rainfall, and it is a vital component of hydrological and climatic factors (Valli et al., 2013; De Luis et al., 2011; Gajbhiye et al. 2016). Time series analysis of rainfall is crucial for making reliable short and long term forecasting of impacts of climate change on water resources and food production (Meshram et al. 2018; Rawat et al. 2018; Banda et al. 2021; Mahato et al. 2021). It is required to understand rainfall variability at the temporal and regional scales to minimise the impact of drought or flood events. It will help for the sustainable utilisation of water resources.

Odjugo (2010a, 2010b) found that global warming and declining rainfall pattern and unreliable pattern of rainfall affect recharge, ponds, lakes, and rivers in most parts of the world, particularly India. It develops water stress conditions and affects millions of people. Change in intensity of rainfall over an area has the probability of disturbing the hydrological cycle (McGuire et al., 2002). Shifting or slow rate in natural phenomena's like rainfall has an impact on water availability, groundwater recharge, modification of fluvial regimes, the likelihood and severity of soil erosion, and increased flood risk probability (De-Luis et al., 2011; Adegun et al., 2012; Ezemonye and Emeribe, 2011; Nzoiwu,2015).
With recent flood in some parts of India (e.g. Chennai, Tamil Nadu) has recorded high rainfall value of 200-340 $\mathrm{mm} /$ day (Mishra 2016), Kerala flood-2019, Odisha flood2019, Northeast (Assam, Nagaland and Manipur) flood-2019, Karnataka flood-2019, Uttar Pradesh-2019, Bihar-2019, Maharashtra-2019, Rajasthan flood-2019, and Madhya Pradesh flood-2019 (http://floodlist.com/tag/india, Flood List is funded by Copernicus, the European system for Earth monitoring), in the other month of 2019 have been studied by many researchers to understand the cause and its impact.

Heavy rainfall events occur in a short period, which produces causes frequent floods and will bring more streamflow. The rainfall total on an annual and seasonal basis need to be analysed, and it will provide information about surplus and deficits of water availability and but rainfall intensity also plays a vital role (De-Luis et al., 2011). The frequency of irregular rainfall has been a major climatic incident in most parts of the world, including India. The study of rainfall intensity for major urban areas in Tamil Nadu, including Chennai, has become a concern to researchers and the government. However, rainfall variations analysis over time scale and their statistical significances are key for estimating flood risks and water resource management. 
Therefore, rainfall indices can be classified based on rainfall time-series frequency analysis using rainfall indices (Kumbuyo et al., 2014). Few indices have been used to estimate rainfall concentration or intensity and variability (De-Luis et al., 2011; Apaydin et al., 2006). These indices, namely Precipitation Concentration Index (PCI) (De-Luis et al., 2011; Oliver, 1980), Precipitation Concentration Period (PCP), Precipitation Concentration Degree (PCD), Simple Daily Intensity Index, and modified Fourier Index (Hernando and Romana 2015)and many other. According to $\mathrm{Du}$ et al. (2020), the PCI provides convenient quantitative characterisations of precipitation variability. Zhang et al. (2019) performed PCI analysis on 597 meteorological stations throughout China to assess the impacts of geographical parameters (latitude, longitude, and altitude). Li et al. (2020) used precipitation concentration in the transitional zone between Qinling Mountains (QDM), Guanzhong Plain (GZP) and the Loess Plateau (LPNS) in China, using monthly-scale precipitation concentration index (PCI) and daily-scale concentration index (CI) from daily rainfall records.

The study objectives were to calculate the rainfall variability and concentration and to assess possible statistical significance and its relation between PCI and rainy days; and between PCI and annual rainfall total.

\section{Methods}

Study area

The Bathinda district of Punjab state of India is famous for agricultural activities (Figure 1a). The study area exists in the southwestern part of the Punjab state and is far from the Shivalik ranges in the North of Punjab. There is no major river passing through it, and the Thar Desert is nearby. In summer temperature is very high, and the climate is tropical steppe, semi-arid and hot (Rawat et al., 2019a; Rawat et al., $2019 \mathrm{~b}$ ). The normal average annual rainfall is 408, and normal monsoon rainfall is $335 \mathrm{~mm}$ (Figure 1b), respectively, and normal rainfall days are only 20.

\section{Data collection}

The daily rainfall dataset was obtained from the Bathinda Meteorological station (Latitude: $30^{\circ} 17^{\prime} \mathrm{N}$, Longitude: $74^{\circ} 58^{\prime} \mathrm{E}$ and Altitude: 211 asl) of the regional Agricultural station of Punjab Agricultural University, Punjab, India. The continuous data of the period 1982-2018 was used for the analysis.

\section{Data analysis}

PCI index was derived by Oliver (1980) and further improved by De-Lius et al. (2011), has been used as rainfall concentration indicator at annual and seasonal scales (wet
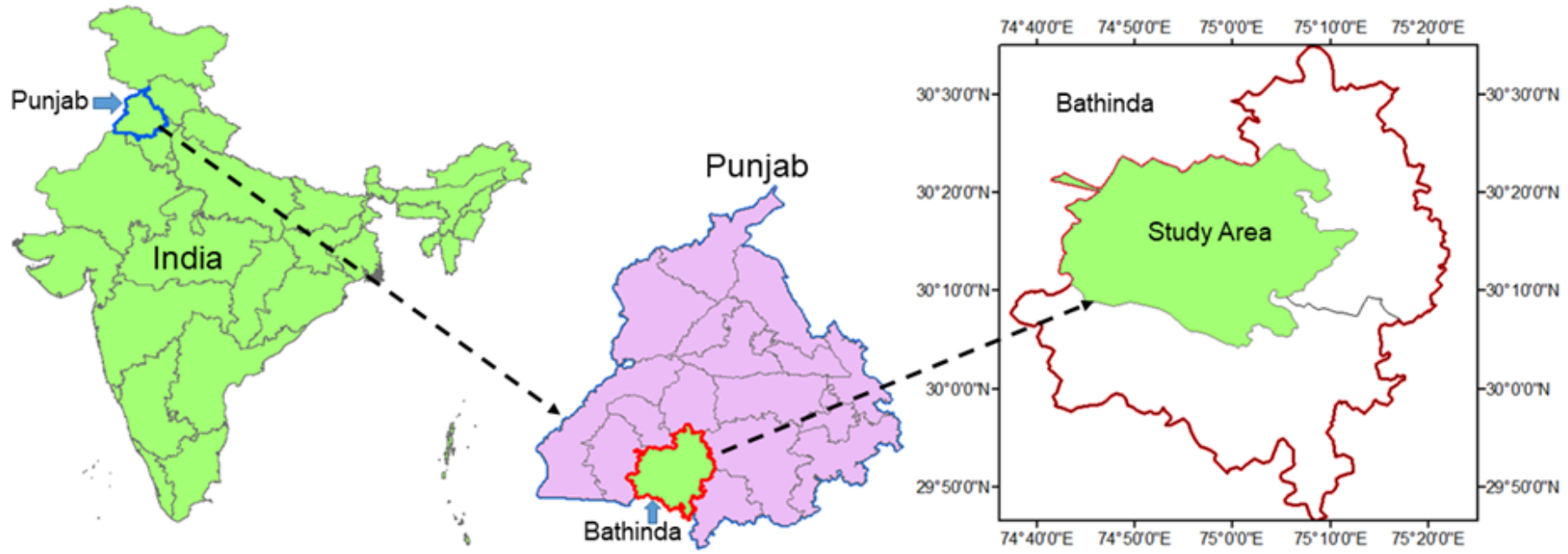

Figure 1a. Study area map

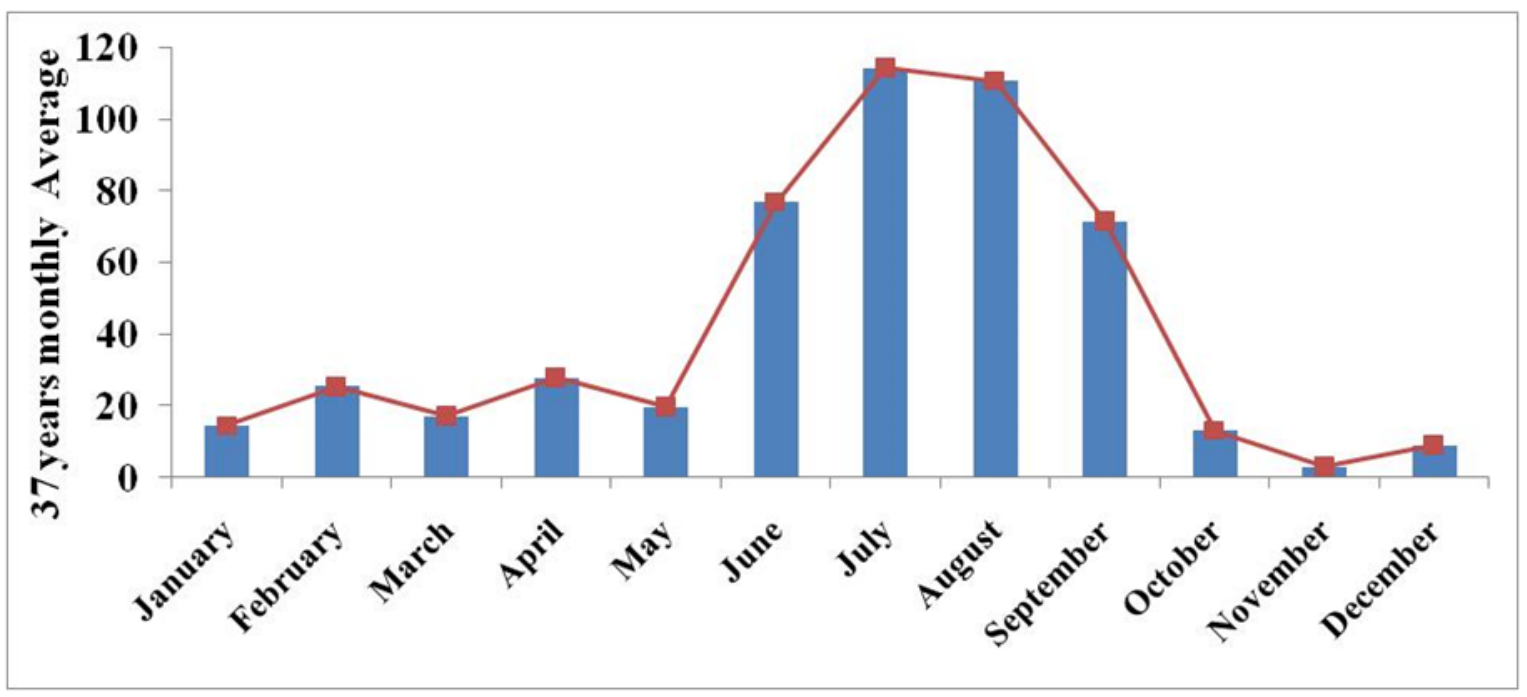

Figure 1b. Thirty-seven years monthly average rainfall of the Bathinda, Punjab, India. 
and dry seasons). We have used PCI, equations (1-5)are expressed below:

$$
\begin{aligned}
& P C I_{\text {annual }}=\frac{\sum_{i=1}^{12} P_{i}^{2}}{\left(\sum_{i}^{12} P_{i}\right)^{2}} \times 100 \\
& P C I_{\text {winter }}=\frac{\sum_{i=1}^{12} P_{i}^{2}}{\left(\sum_{i}^{5} P_{i}\right)^{2}} \times 24.7 \\
& P C I_{\text {pre-monsoon }}=\frac{\sum_{i=1}^{12} P_{i}^{2}}{\left(\sum_{i}^{7} P_{i}\right)^{2}} \times 25.1 \\
& P C I_{\text {monsoon }}=\frac{\sum_{i=1}^{12} P_{i}^{2}}{\left(\sum_{i}^{7} P_{i}\right)^{2}} \times 33.42 \\
& P C I_{\text {post-monsoon }}=\frac{\sum_{i=1}^{12} P_{i}^{2}}{\left(\sum_{i}^{7} P_{i}\right)^{2}} \times 16.71
\end{aligned}
$$

where, $\mathrm{P}_{\mathrm{i}}$ is monthly rainfall of a month $\mathrm{i}$, Annual (12 months or the total number of days 365), winter (December, January, February and a total number of days=90), premonsoon (March, April, May and a total number of days=92), monsoon or rainy season (June, July, August, September and a total number of days $=122$ ), post-monsoon (October, and November and a total number of days=61) for the study area as per Indian Meteorology Department.

Equation 1 has been used for estimating annual PCI, while equations 2, 3, 4 and 5wereused to calculate PCI at a seasonal scale (pre-monsoon, monsoon/rain season, postmonsoon seasons). The categorisation of PCI value, according to Oliver (1980), is tabulated in Table 1. Furthermore, the statistics test (coefficient of determination) was used to develop the relationship between annual rainfall and PCI and between rainy days and PCI. The calculation was performed using Microsoft Excel in Windows 7 platform.

Table 1. PCI range and categorisation (Oliver, 1980)

\begin{tabular}{ll}
\hline PCI Value & Significance (Temporal Distribution) \\
\hline PCI $\leq 10$ & $\begin{array}{l}\text { Uniform Precipitation Distribution (UPD) } \\
\text { or low precipitation concentration (LPD) } \\
\text { Moderate Precipitation Distribution } \\
\text { PCI } \geq 10 \leq 15\end{array}$ \\
PCI $>15 \leq 20$ & $\begin{array}{l}\text { Irregular Precipitation Distribution (IPD) } \\
\text { PCI }>20\end{array}$ \\
& $\begin{array}{l}\text { Strong Irregularity of Precipitation } \\
\text { Distribution (SIPD) }\end{array}$ \\
\hline
\end{tabular}

\section{Results and Discussion}

The result of the PCI on an annual basis for the Bathinda Meteorological station is shown in Figure 2. The lowest value was 14.96 during the year 2006 and which fell in a moderate precipitation distribution bin. During the analysis of $\mathrm{PCI}_{\text {Annual }}$, the highest value of 44.82 was found in 2000, which lies under strong irregularity of precipitation distribution class. Figure 2 suggests that Bathinda received a good amount of annual rainfall, but it was fully irregular from its normal rainfall pattern for the study area. $\mathrm{PCI}_{\text {Annual }}$ plotted graph also reveal that study area come under strong irregularity of precipitation distribution (SIPD) class, 22 (or $59.5 \%$ of the 37 years) time out of 37 years, while only one-time study area comes under moderate precipitation distribution (MPD) category in 37 years of span. From PCI annual analysis, it is clear that $59.5 \%$ of the year was classified as SIPD, indicating that during the last 37 years, most of the year rainfall distribution/concentration was irregular.

The mean $\mathrm{PCI}_{\text {Annual }}$ Value was found 23.22 of the 37 years (1982-2018), only 17 times of these years $\mathrm{PCI}_{\mathrm{Annual}}$ value was above the mean value $(=23.22$, Table 2$)$, while 20 (54\% of the total year) year was below the mean (Fig. 3). The mean $\mathrm{PCI}_{\text {Annual }}$ value comes under the SIPD class; if we fixed the mean $\mathrm{PCI}_{\text {Annual }}$ value as 20 than only 15 times, it falls below the SIPD class. In both cases, mean $\mathrm{PCI}_{\text {Annual }}(23.22$ or 20 ) falls under the SIPD class. Thus, rainfall concentration/ distribution within the study area and during the study period was not regular based on $\mathrm{PCI}_{\text {Annual }}$ (Fig. 2) and $\mathrm{PCI}_{\text {Annual }}$ anomalies (Fig. 3). This nature of rainfall within the study area may be revealing the impact of climate change on rainfall patterns.

\section{Seasonal scale analysis}

Thirty-seven years of a span only two times (1992 and 2001) $\mathrm{PCI}_{\text {winter }}$ value was less than 10, which revealed UPD or LPC. PCI $_{\text {winter }}$ graph (Fig. 4A) showed that most of the year (54\% of the total year) rainfall distribution was under the MPD category while sometimes SPD and ISPD respectively, 9 (24\%) and 5 (13\%). Overall this period (Dec to Feb) rain distribution is very important for wheat crop production within the study area. Fig 4B revealed anomalies in winter rain distribution. $\mathrm{PCI}_{\text {winter rain }}$ anomalies represent an event that how many times winter rainfall was less or higher from the average value (14.96) of $\mathrm{PCI}_{\text {winter rain }}$. Therefore it is clearly represented that only 14 times out of 37 years, the study area has more than average rainfall destitution. Fig. 4B represents anomalies in PCI pre-monsoon for pre-monsoon season.

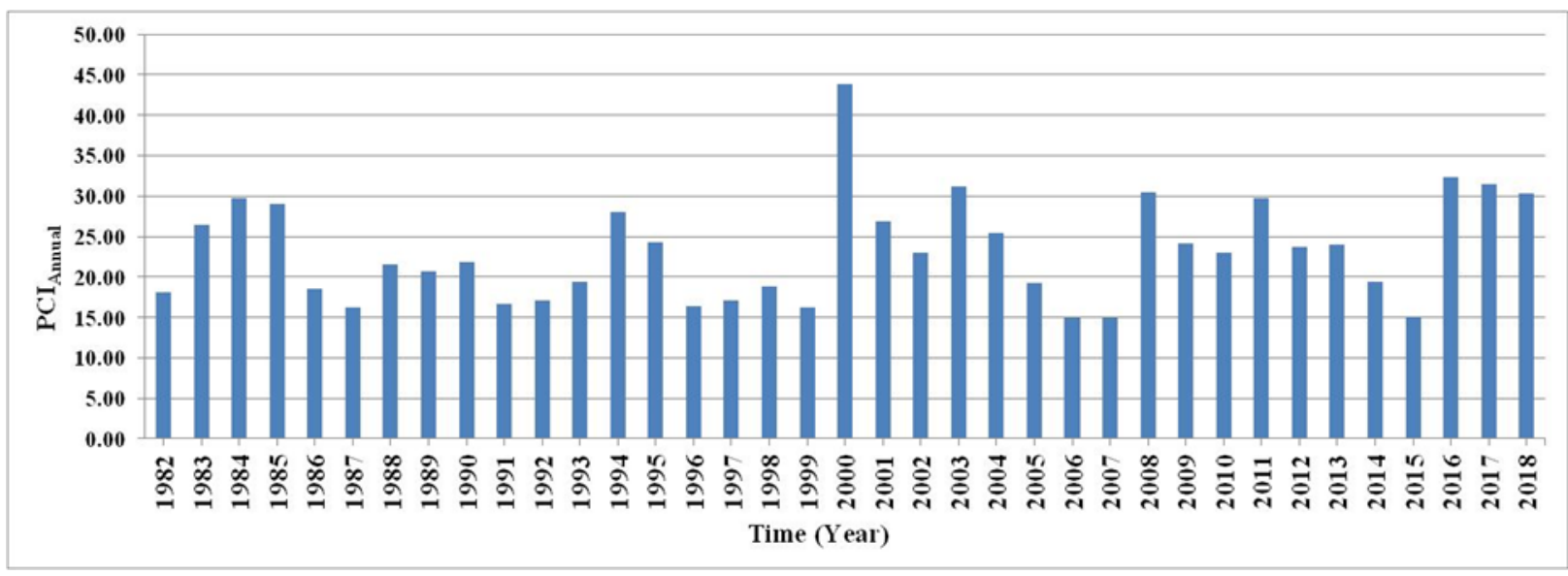

Figure 2. Annual Precipitation Concentration Index $\left(\mathrm{PCI}_{\mathrm{Annual}}\right)$ for Bathinda, Punjab, India 


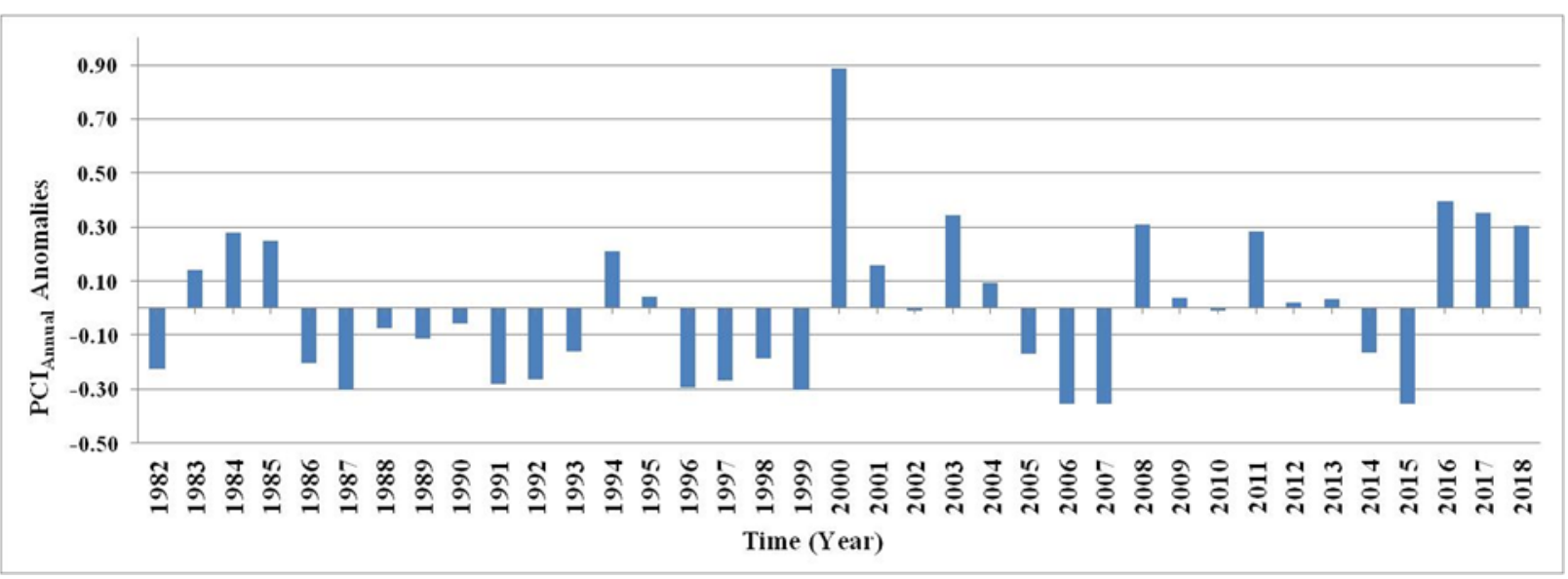

Figure 3. Annual Precipitation Concentration Index $\left(\mathrm{PCI}_{\mathrm{Annual}}\right)$ anomalies for Bathinda, Punjab, India

Table 2. Mean, Maximum and Minimum decadal values of Seasonal and Annual Precipitation Concentration Index for Bathinda

\begin{tabular}{|c|c|c|c|c|c|}
\hline $1982-1991$ & $\mathrm{PCI}_{\text {Annual }}$ & $\mathrm{PCI}_{\text {Winter }}$ & $\mathrm{PCI}_{\text {Pre-monsoon }}$ & $\mathrm{PCI}_{\text {Monsoon }}$ & $\mathrm{PCI}_{\text {Post-monsoon }}$ \\
\hline Mean & 21.87 & 14.79 & 12.76 & 13.61 & 15.93 \\
\hline Max & 29.71 & 24.70 & 16.27 & 24.17 & 16.71 \\
\hline Min & 16.19 & 10.06 & 9.29 & 11.04 & 11.59 \\
\hline 1992-2001 & & & & & \\
\hline Mean & 22.80 & 14.33 & 11.45 & 11.51 & 13.27 \\
\hline Max & 43.82 & 24.70 & 16.73 & 21.52 & 16.71 \\
\hline $\begin{array}{l}\text { Min } \\
2002-2011\end{array}$ & 16.18 & 0.00 & 0.00 & 8.62 & 0.00 \\
\hline Mean & 23.62 & 15.56 & 15.86 & 12.11 & 8.42 \\
\hline Max & 31.22 & 24.70 & 25.10 & 15.23 & 16.71 \\
\hline $\begin{array}{l}\text { Min } \\
2012-2018\end{array}$ & 14.96 & 12.38 & 8.57 & 9.27 & 0.00 \\
\hline Mean & 25.16 & 15.33 & 13.73 & 12.72 & 10.55 \\
\hline Max & 32.37 & 24.70 & 25.10 & 16.29 & 16.71 \\
\hline $\begin{array}{l}\text { Min } \\
1982-2018\end{array}$ & 15.02 & 10.39 & 8.50 & 9.77 & 0.00 \\
\hline Mean & 23.22 & 14.96 & 13.43 & 12.47 & 12.16 \\
\hline Max & 43.82 & 24.70 & 25.10 & 24.17 & 16.71 \\
\hline Min & 14.96 & 0.00 & 0.00 & 8.62 & 0.00 \\
\hline
\end{tabular}

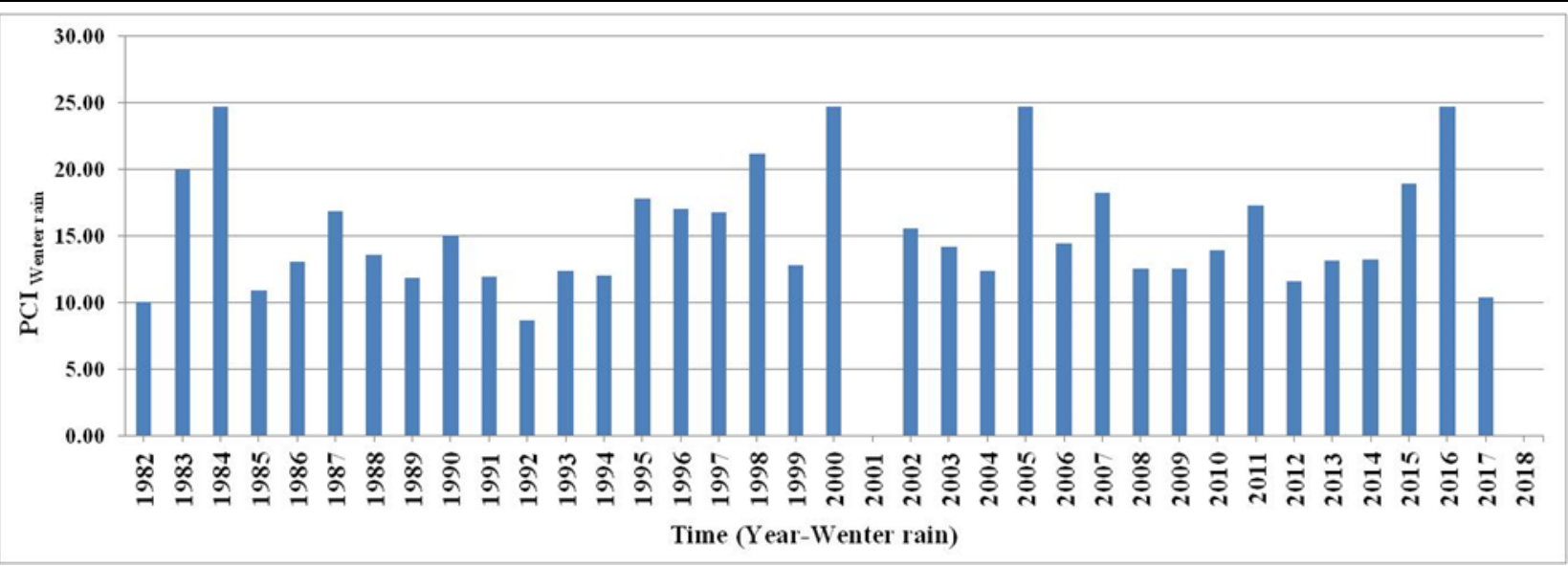

Figure 4A. Precipitation Concentration Index for winter rain in Bathinda, Punjab, India 


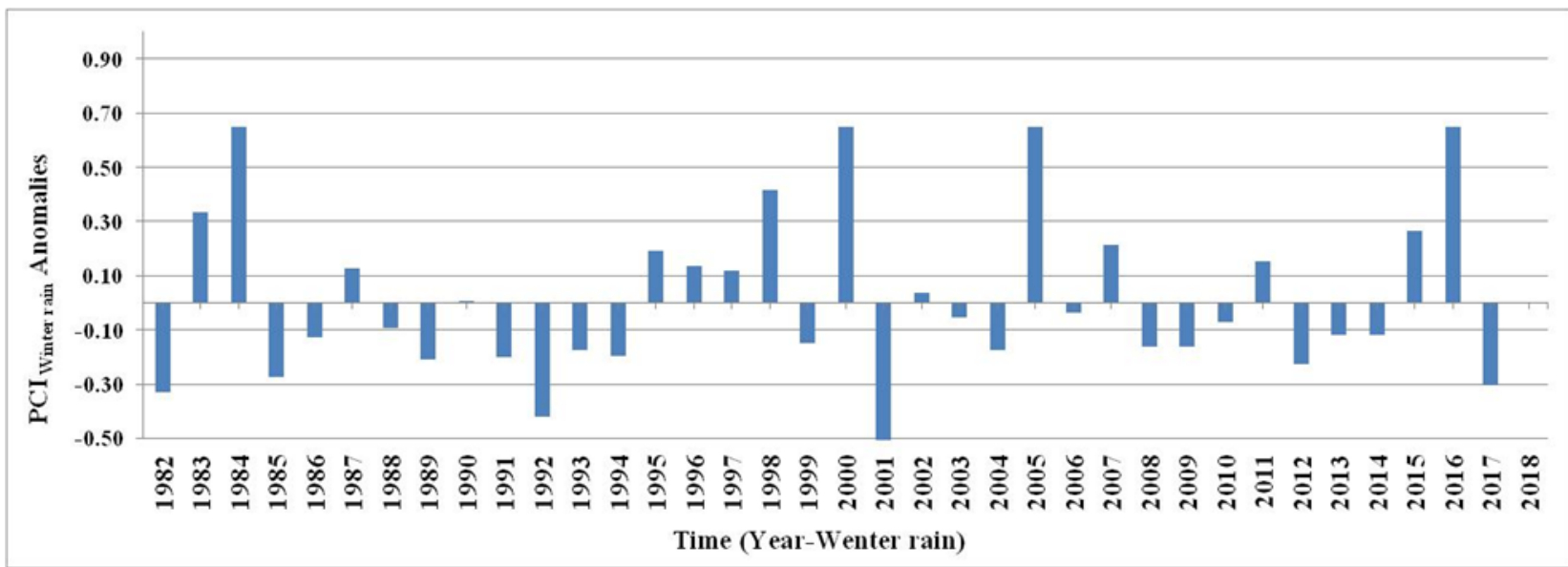

Figure 4B. Precipitation Concentration Indexwinter rain anomalies for Bathinda, Punjab, India

Graph (Figure 4B) represent the maximum -1 value during the year 2000 because this year, no rainfall was received by the study area during pre-monsoon. Table 2 showed a mean value (14.96) of 37 years. Hence, the study area falls under the MPD category.

From Figure 5A, plotted PCI for the pre-monsoon (March to May) season of the study area. According to Fig 5A, during 2002, 2004, 2010, 2012 and 2017, rainfall distribution for pre-monsoon season was ISPD because $\mathrm{PCI}_{\text {pre-monsoon }}$ value was greater than 20 . The year 2000 showed zero value of $\mathrm{PCI}_{\text {pre-monsoon }}$ because, in this year, there was no rainfall from March to May. From 1982 to 1999, rainfall distribution during pre-monsoon was normal, but after 2000 to 2017 , there was a random pattern. Generally, during this period (March to May) study area has received rainfall due to only local disturbances in the atmosphere. Out of 37 , only 15 times PCI value more than average value (13.43, Table 2 ). This figure also reveals that the study area was under the UPD/LDP and MDP class most of the time because the graph has more negative value concerning positive value; it can be possible if the study area received less PCI from the 37 -year average value PCI.

Figure 6A represented 37 years (1982-2018) PCI of monsoon years. Fig. 6A showed only six times (in 1992, 1996, 1999,2010 and 2015) rainfall PCI or $\mathrm{PCI}_{\text {monsoon was below the }}$ 10 (or under the UPD/LPC class). From Fig 6A, it is evident that the distribution of $\mathrm{PCI}_{\text {monsoon }}$ during the last 37 years was under the MPD (or in ranges of $\geq 10 \leq 15$ ). Only two times (in the years 1982 and 2000)PCI monsoon crossed the IPD $(\geq 15$ $\leq 20)$ limit into SIPD $(>20)$. These two years rainfall was highly irregular from the regular pattern of the study area. Based on the average value of 37 years, $\mathrm{PCI}_{\text {monsoon }}$ is 12.46 (Table 2), which classified $\mathrm{PCI}_{\text {monsoon }}$ of the study area as MPD. Based on Fig. 6B, most of the time $\mathrm{PCI}_{\text {monsoon }}$ value was below the average value due to this fact more negative value received by the study area in the last 37 years. Only two times (1982 and 2000) rainfall distribution was more than average; therefore, these years have high positive value retained by study area. Similar years 1992, 1999 and 2010 were highly negative (in range of -0.32 to -0.26 ), which revealed that these three years of rainfall concentration was were uniform within the study area.

Figure 7A represent post-monsoon (October and November) PCI of 37 years for the study area. The distribution of PCI (post-monsoon) gives vital information about October and November rainfall concentrations. In the last 37 years, the study area accrued random rainfall events during October month and rainfall under the IPD category (PCI $>15 \leq 20)$. In the last 37 years, only seven-time (in a year) no rainfall during October and November. According to Table 2 study area has 37 years average PCI (postmonsoon) value of 12.16. Therefore, the study area must have come under the MPD category (PCI $>10 \leq 15)$. But from Fig. $7 \mathrm{~A}$, most of the time study area exists in a range of PCI $>15$ $\leq 20$, this contradiction is due to averaging process because seven-time PCI (post-monsoon) values were zero, which reduces the average value of PCI (post-monsoon). Fig. 7B, 2000, 2003, 2009, 2010, 2011 and 2018 have a maximum negative value (or -1 ) because the study area has no rainfall during these years (only during October and November).

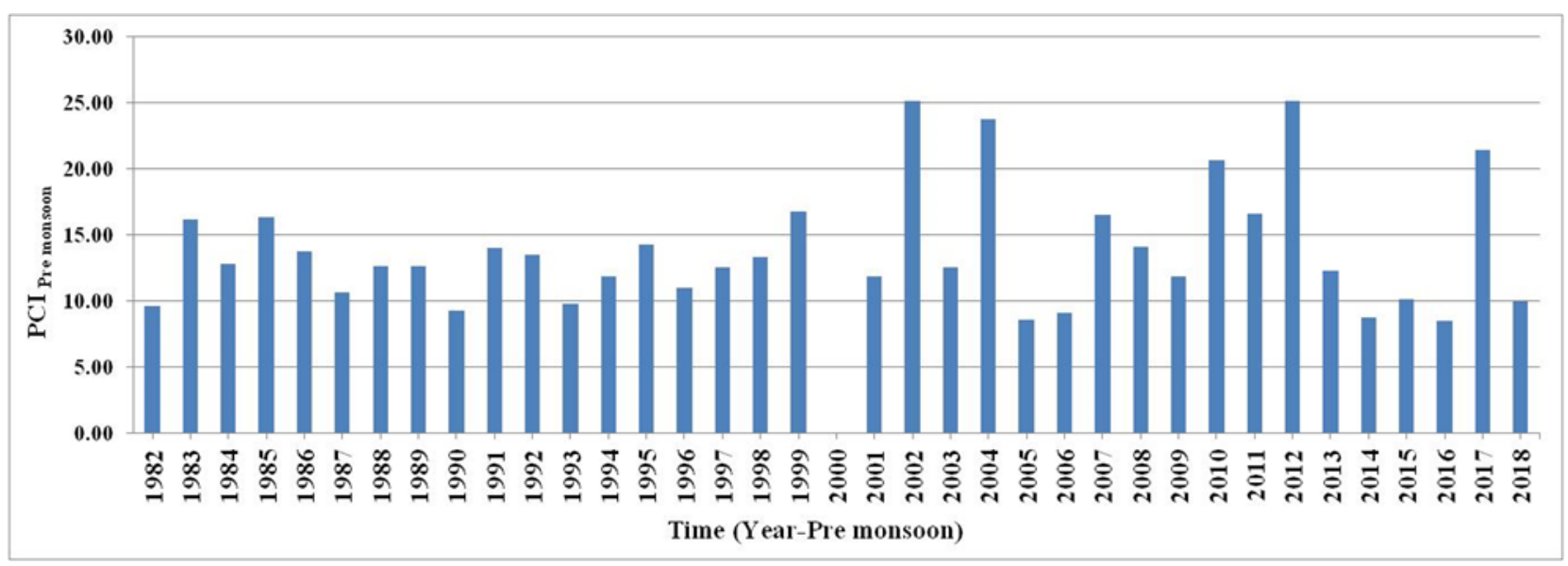

Figure 5A. Precipitation Concentration Index for pre-monsoon in Bathinda, Punjab, India 


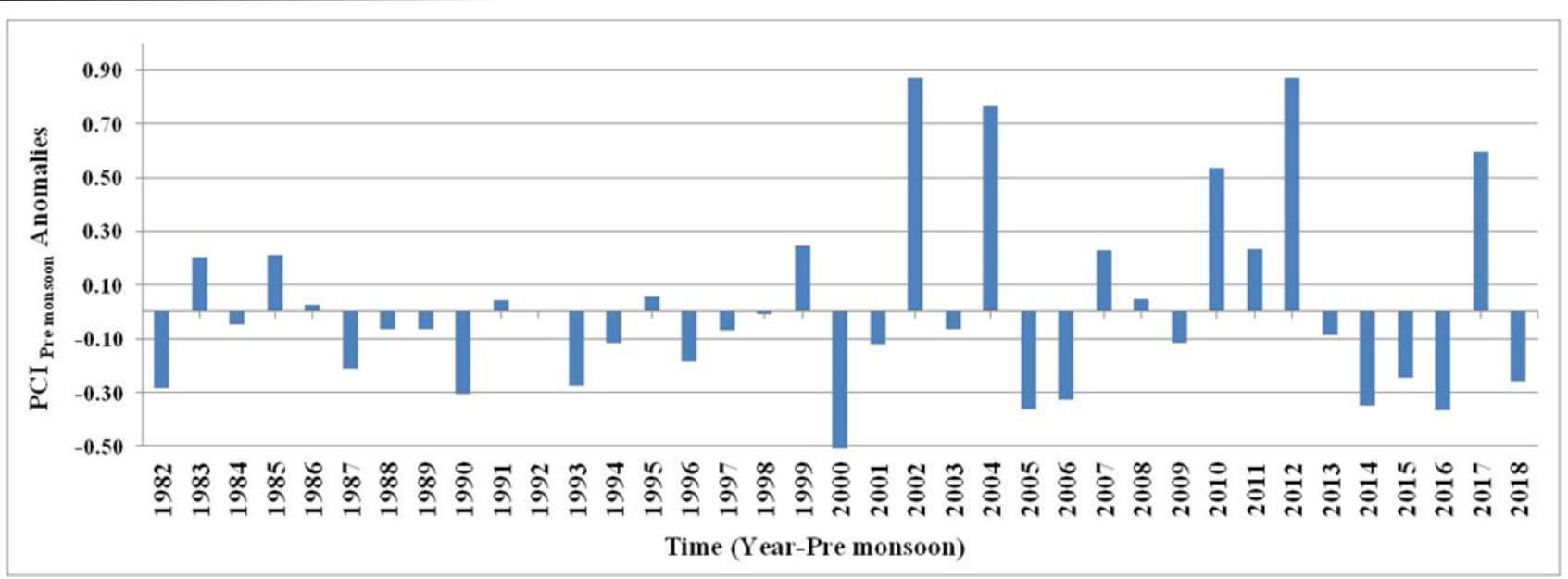

Figure 5B. Precipitation Concentration Indexpre monsoon anomalies for Bathinda, Punjab, India

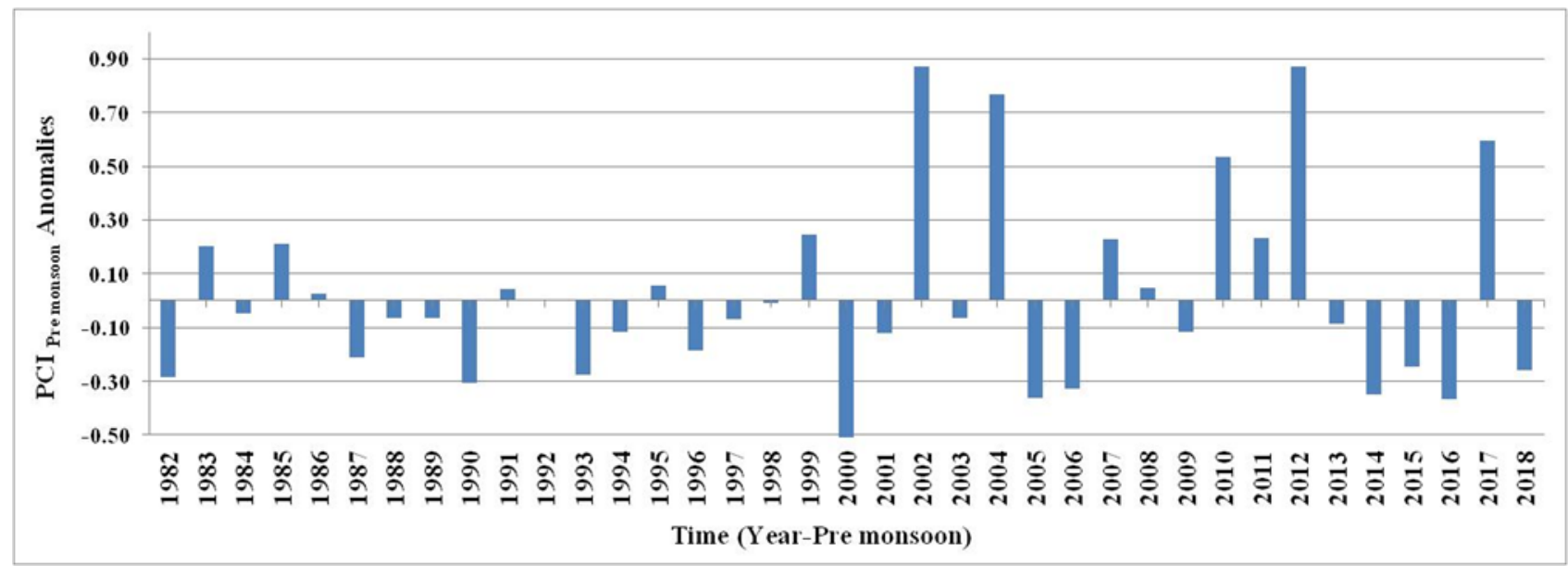

Figure 5B. Precipitation Concentration Indexpre monsoon anomalies for Bathinda, Punjab, India

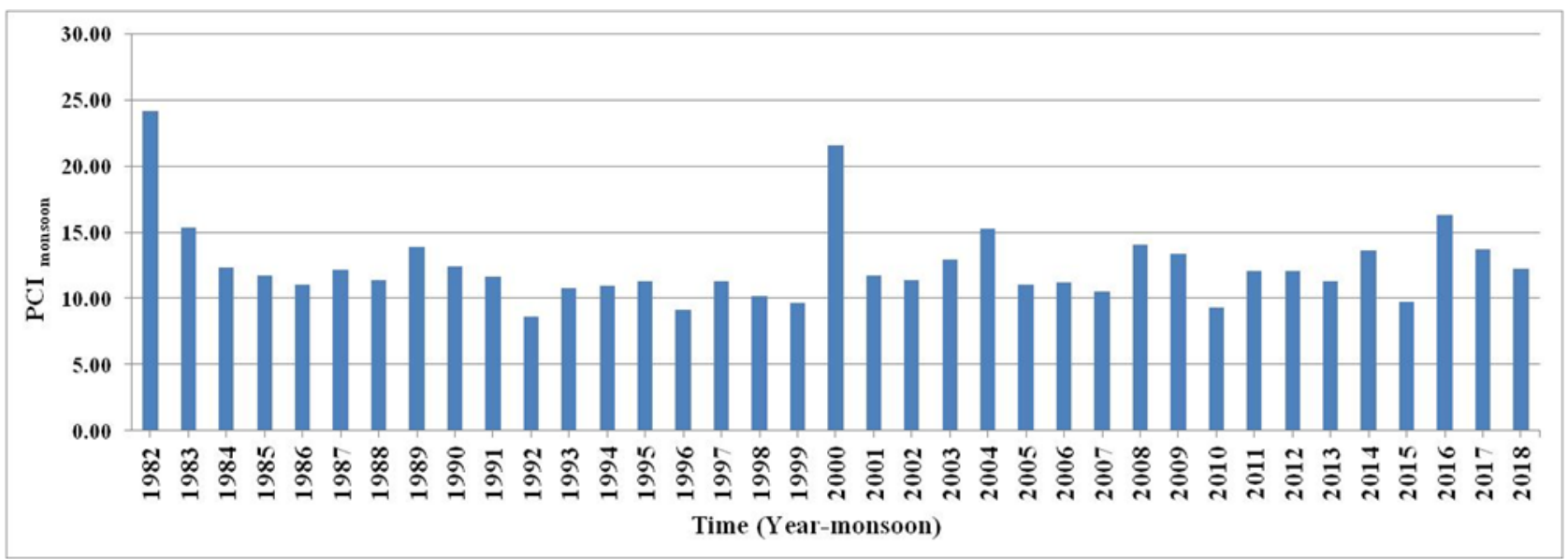

Figure 6A. Precipitation Concentration Index monsoon for Bathinda, Punjab, India 


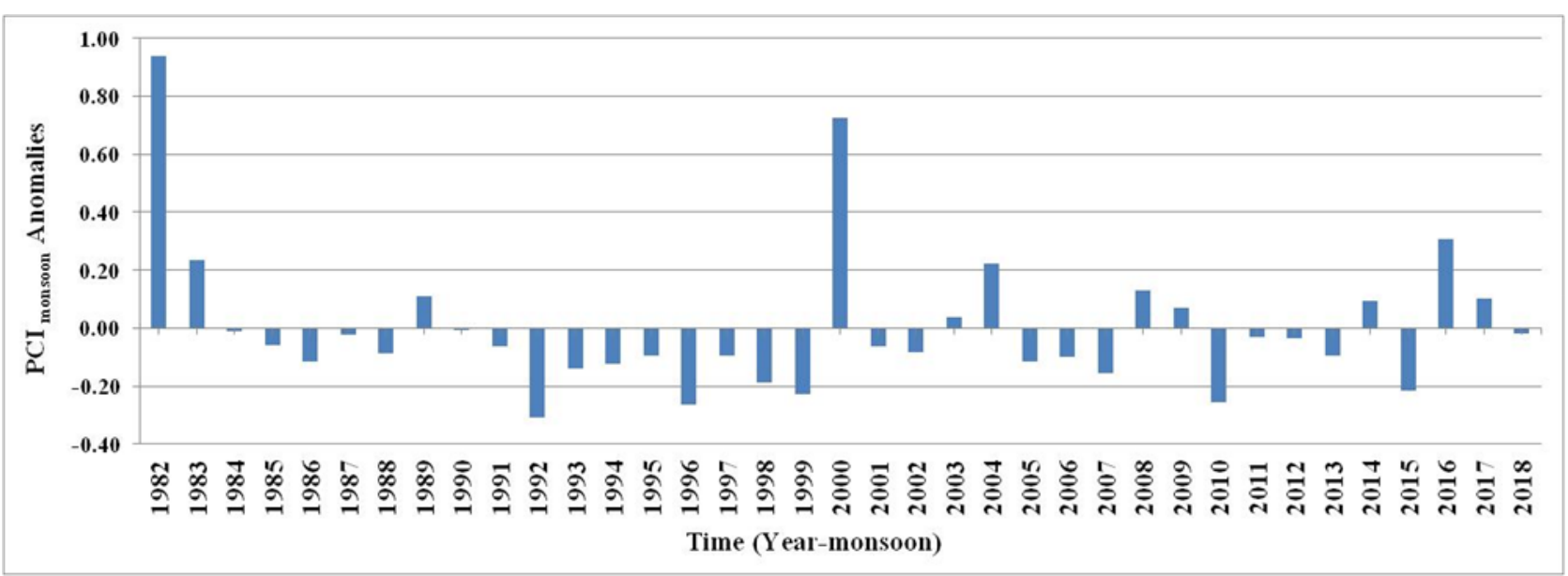

Figure 6B. Precipitation Concentration Index monsoon anomalies for Bathinda, Punjab, India

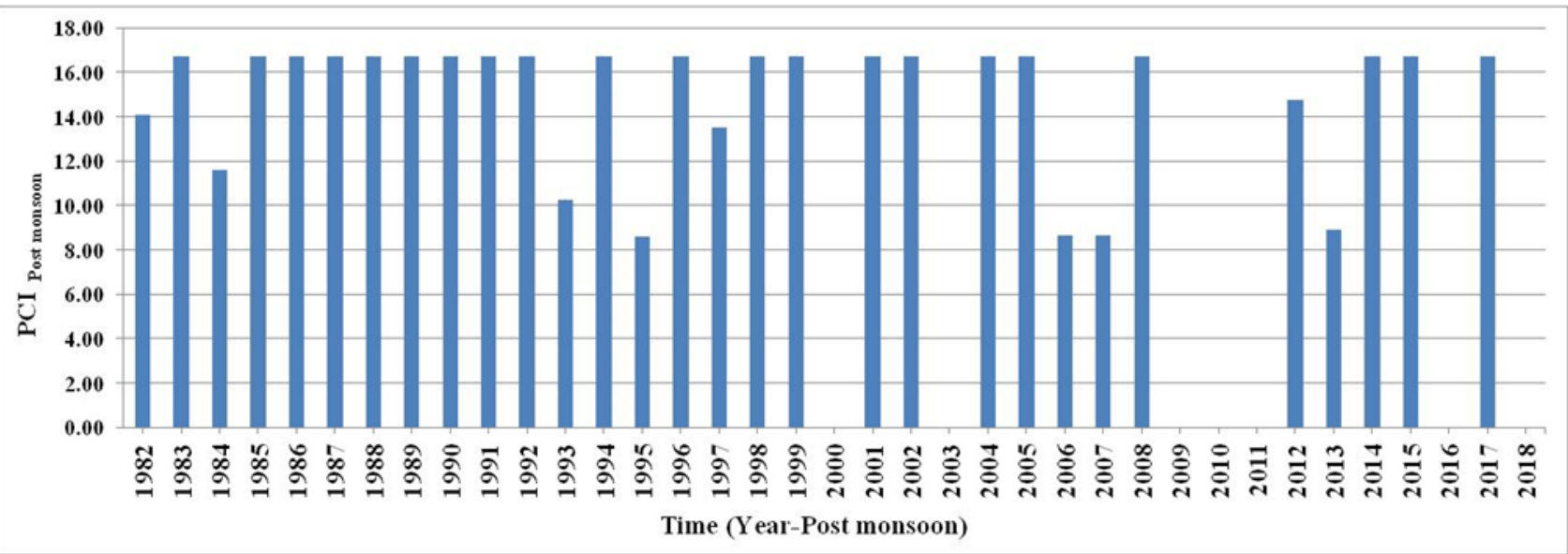

Figure 7A. Precipitation Concentration Index post-monsoon for Bathinda, Punjab, India

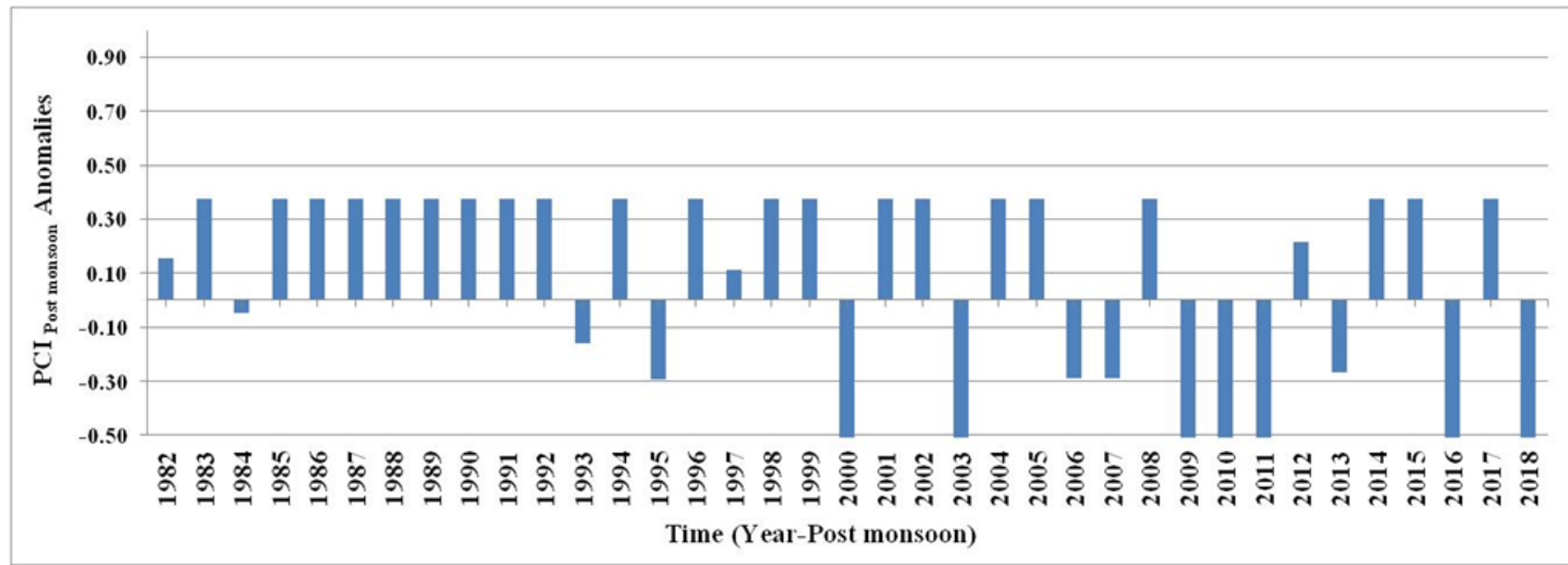

Figure 7B. Precipitation Concentration Index post-monsoon anomalies for Bathinda, Punjab, India

\section{Decadal variations in PCI}

Further, the PCI on decade results are tabulated in Table 2 . On the decadal scale, the annual PCI for 1982-1991,19821991, 1992-2001, 2002-2011 and 2012-2018 (only six years) fall within the SIPD (PCI >20), PCI category giving an average value of $21.87,22.80,23.62$ and 25.16 , respectively. Each decadal span value of PCI is increasing in order which is identified as SIPD. Table 2 suggest the climate change effect over the annual rainfall distribution pattern. For the winter season rain, the PCI value for the four decades showed an increasing tendency. Table 2 revealed that winter rain PCI gradually increased toward the IPD from MPD.
Decadal analysis of post-monsoon PCI also indicates an increasing order (if in next four years 2019, 2020, 2021 and 2022, PCI post-monsoon $>15.86$ ). Table 2 represents monsoon rain PCI is increasing mode but slightly and showing a random distribution.

To additional characterise the trend of PCI in Bathinda, regression statistics (Multiple $\mathrm{R}, \mathrm{R}^{2}$, Adjusted $\mathrm{R}^{2}$ ) tests was used to evaluate its relationship $\left(\mathrm{PCI}_{\mathrm{Annual}} \mathrm{PCI}_{\text {Winter }} \mathrm{PCI}_{\mathrm{Pre} \text { - }}\right.$ monsoon $\mathrm{PCI}_{\text {Monsoon }}$ and $\mathrm{PCI}_{\text {Post-monsoon }}$ ) with the number of rainfall days (during annual, winter, pre-monsoon, monsoon and post-monsoon) at a different span of years. A positive and statically significant correlation $\left(\mathrm{R}^{2}=0.68\right)$ for the 1992 to 
2001 span (Table 3 and Fig. 8A) was observed between $\mathrm{PCI}_{\text {Annual }}$ and the annual number of rainfall days at a 0.05 confidence level. Whereas Table 4 and Fig. 8B revealed that there is no statistically significant correlation existed between PCI $\quad\left(\mathrm{PCI}_{\text {Annual }} \quad \mathrm{PCI}_{\text {Winter }} \quad \mathrm{PCI}_{\text {Pre-monsoon }} \mathrm{PCI}_{\text {Monsoon }}\right.$ and
$\mathrm{PCI}_{\text {Post-monsoon }}$ ) and total rainfall in different spans of years at 0.05 confidence level because all $\mathrm{R}^{2}$ value for any year of the span is $<0.5$ (Fig. 8B). This number implies that PCI is expected to increase with increment in the number of rainy days (in 2012-2018, Table 3 and Fig. 8A) for Bathinda.

Table 3. Regression Statistics between PCI and numbers of rainfall days in different spans of years

\begin{tabular}{cccccc}
\hline 1982-2018 & $\mathrm{PCI}_{\text {Annual }}$ & $\mathrm{PCI}_{\text {Winter }}$ & $\mathrm{PCI}_{\text {Pre-monsoon }}$ & $\mathrm{PCI}_{\text {Monsoon }}$ & $\mathrm{PCI}_{\text {Post-monsoon }}$ \\
\hline Multiple R & 0.55 & 0.09 & 0.30 & 0.48 & 0.47 \\
$\mathrm{R}^{2}$ & 0.31 & 0.01 & 0.09 & 0.23 & 0.22 \\
Adjusted R & 0.29 & -0.02 & 0.07 & 0.21 & 0.20 \\
Standard Error & 8.60 & 3.70 & 4.30 & 6.36 & 1.44
\end{tabular}

$1982-1991$

\begin{tabular}{|c|c|c|c|c|c|}
\hline Multiple R & 0.24 & 0.15 & 0.38 & 0.30 & 0.33 \\
\hline $\mathrm{R}^{2}$ & 0.06 & 0.02 & 0.14 & 0.09 & 0.11 \\
\hline Adjusted $\mathrm{R}^{2}$ & -0.06 & -0.10 & 0.04 & -0.02 & 0.00 \\
\hline Standard Error & 4.66 & 3.53 & 5.09 & 7.73 & 0.88 \\
\hline
\end{tabular}

$1992-2001$

Multiple R

0.83

0.68

0.64

8.41

0.15

0.41

0.17

0.06

4.68

3.94

0.72

0.26

0.02

0.52

0.07

Adjusted $\mathrm{R}^{2}$

$-0.10$

0.46

$-0.05$

Standard Error

2002-2011

Multiple R

0.24

0.43

0.19

0.08

4.31

8.77

$-0.06$

Standard Error

0.80

0.09

0.75

0.82

$\mathrm{R}^{2}$

0.63

0.01

0.56

0.67

0.59

Adjusted R ${ }^{2}$

0.56

$-0.24$

0.47

0.60

0.51

Standard Error

5.50

2.79

2.30

3.40

0.80 
Table 4. Regression Statistics between PCI and total rainfall in different spans of years

\begin{tabular}{|c|c|c|c|c|c|}
\hline 1982-2018 & $\mathrm{PCI}_{\text {Annual }}$ & $\mathrm{PCI}_{\text {Winter }}$ & $\mathrm{PCI}_{\text {Pre-monsoon }}$ & $\mathrm{PCI}_{\text {Monsoon }}$ & $\mathrm{PCI}_{\text {Post-monsoon }}$ \\
\hline Multiple R & 0.34 & 0.02 & 0.25 & 0.47 & 0.31 \\
\hline $\mathrm{R}^{2}$ & 0.12 & 0.00 & 0.06 & 0.22 & 0.09 \\
\hline Adjusted $\mathrm{R}^{2}$ & 0.09 & -0.03 & 0.04 & 0.20 & 0.07 \\
\hline Standard Error & 6.16 & 5.15 & 4.92 & 2.74 & 6.30 \\
\hline \multicolumn{6}{|l|}{$1982-1991$} \\
\hline Multiple R & 0.30 & 0.28 & 0.32 & 0.66 & 0.21 \\
\hline $\mathrm{R}^{2}$ & 0.09 & 0.08 & 0.10 & 0.44 & 0.04 \\
\hline Adjusted $\mathrm{R}^{2}$ & -0.02 & -0.04 & -0.01 & 0.37 & -0.08 \\
\hline Standard Error & 5.00 & 4.66 & 2.44 & 3.11 & 1.80 \\
\hline \multicolumn{6}{|l|}{$1992-2001$} \\
\hline Multiple R & 0.66 & 0.00 & 0.27 & 0.65 & 0.29 \\
\hline $\mathrm{R}^{2}$ & 0.44 & 0.00 & 0.07 & 0.42 & 0.08 \\
\hline Adjusted $\mathrm{R}^{2}$ & 0.37 & -0.12 & -0.04 & 0.35 & -0.03 \\
\hline Standard Error & 6.83 & 7.32 & 4.55 & 2.96 & 5.64 \\
\hline \multicolumn{6}{|l|}{$2002-2011$} \\
\hline Multiple R & 0.29 & 0.50 & 0.25 & 0.21 & 0.42 \\
\hline $\mathrm{R}^{2}$ & 0.09 & 0.25 & 0.06 & 0.04 & 0.18 \\
\hline Adjusted $\mathrm{R}^{2}$ & -0.03 & 0.15 & -0.06 & -0.08 & 0.07 \\
\hline Standard Error & 5.99 & 3.47 & 5.95 & 1.85 & 7.58 \\
\hline \multicolumn{6}{|c|}{ 2012-2018 (7 year span) } \\
\hline Multiple R & 0.18 & 0.04 & 0.51 & 0.26 & 0.69 \\
\hline $\mathrm{R}^{2}$ & 0.03 & 0.00 & 0.26 & 0.07 & 0.48 \\
\hline Adjusted $\mathrm{R}^{2}$ & -0.16 & -0.25 & 0.11 & -0.12 & 0.38 \\
\hline Standard Error & 7.07 & 6.08 & 6.34 & 2.21 & 6.09 \\
\hline Multiple R & 0.18 & 0.04 & 0.51 & 0.26 & 0.69 \\
\hline
\end{tabular}

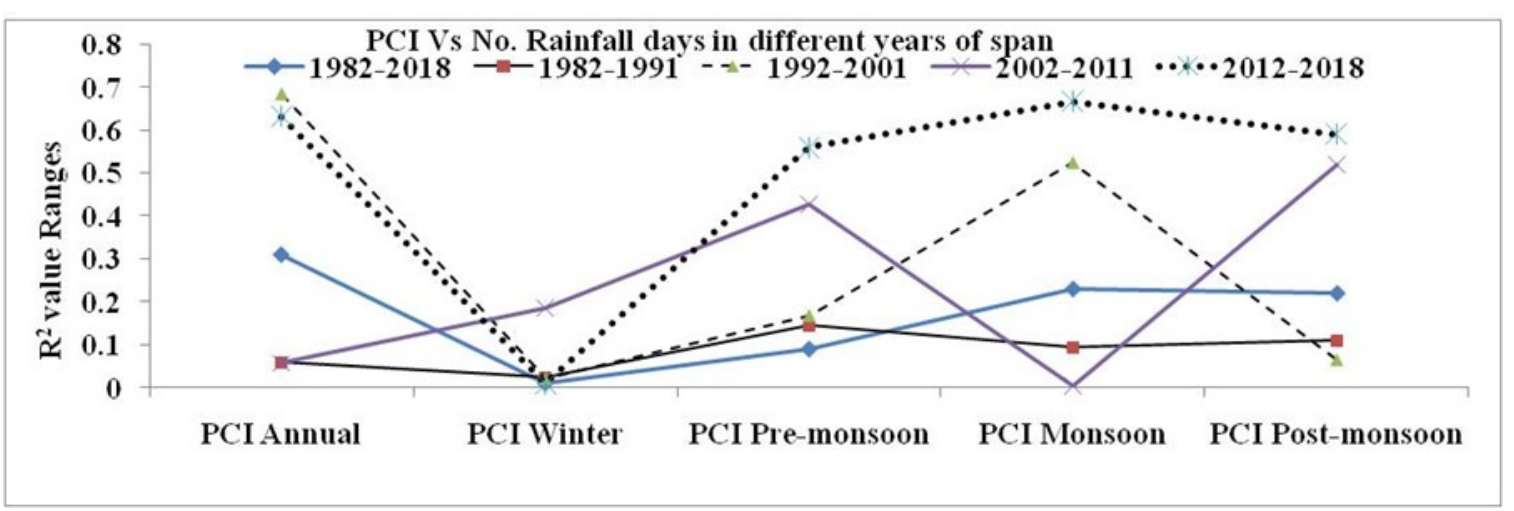

Figure $8 \mathrm{~A} . \mathrm{R}^{2}$ value between PCI and number of rainfall days at the different year of span 


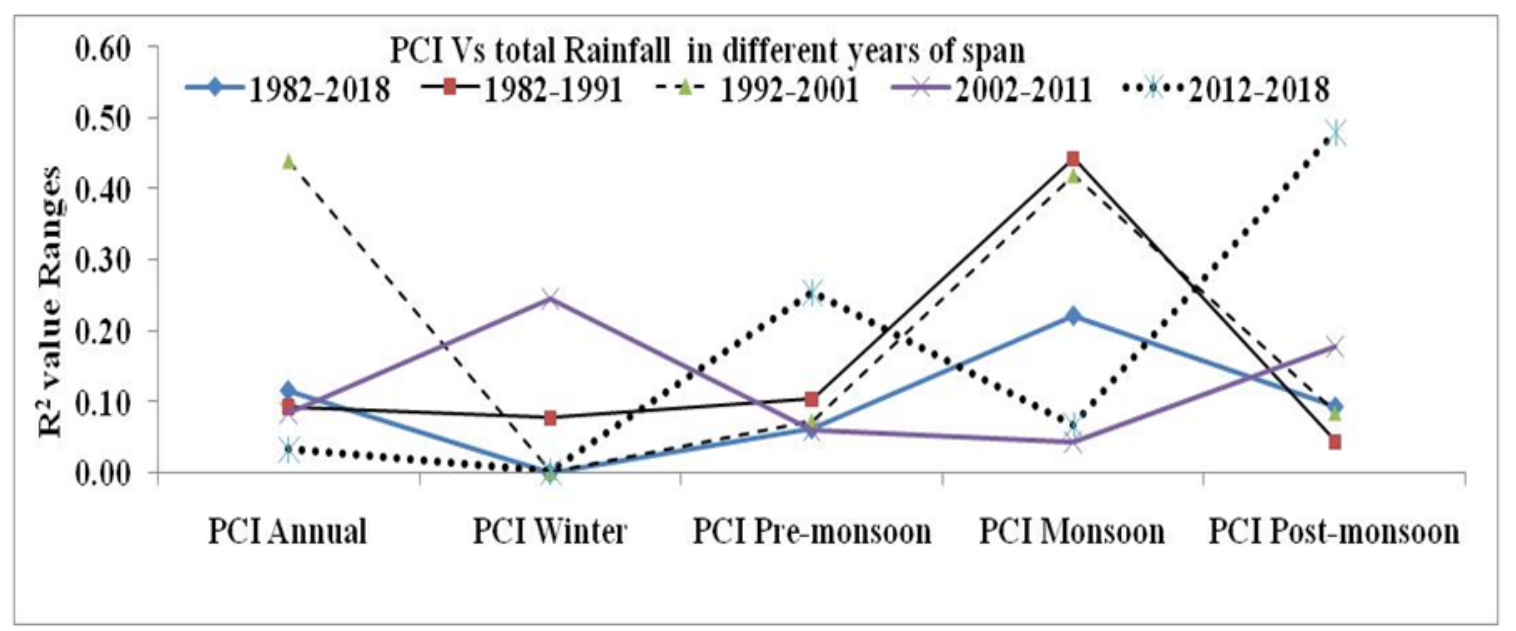

Figure $8 \mathrm{~B} . \mathrm{R}^{2}$ value between PCI and total rainfall at the different year of span

\section{Discussion}

The study revealed that rainfall and $\mathrm{PCI}_{\text {Annual, }} \mathrm{PCI}_{\text {Winter, }}$ $\mathrm{PCI}_{\text {Pre-monsoon, }} \mathrm{PCI}_{\text {Monsoon }}$ \& $\mathrm{PCI}_{\text {Post-monsoon }}$ index are in changing mode. On the span of 37 years (1982-2018), PCI on an annual scale was recorded in the range of 43.82 (highest value) to 14.96 (lowest value) with the average value of 23.22 and in both cases (average and maximum) $\mathrm{PCI}_{\text {Annual }}$ come under the SIPD class. A decadal-scale of PCIAnnual indicates that in each decadal span, $\mathrm{PCI}_{\text {Annual }}$ mean value is in increment mode and such type of increasing pattern is continuous. In further decades, $\mathrm{PCI}_{\text {Annual }}$ will be toward the hyper SIPD limit and a new class as hyper SIPD to define the beyond the SIPD limit. Table 2 also revealed a slow rising pattern in a mean value of $\mathrm{PCI}_{\mathrm{Winter}}$ and if this slow rising is maintained in a further decade, winter rain PCI will cross the IPD limit. This fact implies that the rainfall trend in Bathinda is not uniformly distributed (or UPD/LPD limit almost will vanish in near further decadal) but had fluctuated among the MPD, IPD, SIPD and Hyp-SIPD limit. The $59.5 \%$ of the years were characterised by $\mathrm{PCI}_{\mathrm{Annual}}$ value within the SIPD range (>20), while $37.8 \% \mathrm{PCI}_{\text {Annual }}$ value ranged from 16 to 20 (representative PD). This evidence revealed that such irregular rainfall recorded for the $97.3 \%(=59.5+37.8)$ of 37 years could have high soil loss from the study area (Iskander et al., 2014). Meanwhile, similar evidence was not observed for seasonal scales (winter, monsoon pre-monsoon and postmonsoon). Bathinda is characterised by 3 months of winter rain, 3 months pre-monsoon (March, April, May) rain, 4 months of monsoon (June, July, August, September) rain and 2 months post-monsoon (October and November) rain season. $\mathrm{PCI}_{\text {monsoon }}$ was $73 \%$ for the 37 years under the MPD range; $56.8 \%$ of the years yielded a $\mathrm{PCI}_{\text {post-monsoon value come }}$ under the range of $15<\mathrm{PCI}_{\text {post monsoon }}>20$ (IPD); $13 \%$ are within the MPD range. The PCI of the different seasons gives the study area's inclination to flooding and soil erosion due to the weak nature of the soil practical bonding, its profile and underlying geology once exposed as a result of deforestation and urbanisation to the vagaries of weather. The present analysis also evaluated the possible relationship between PCI of different seasons and the number of rain days in different seasons using the $\mathrm{R}^{2}$ test. There is no relationship between PCI and the number of rain days (at different season levels) in the year 1982-2018, 1982-1919 and 2002-2011; there is no relationship between PCI and the number of rain days (at different season level). During the 1992-2001 year of span, a good $\mathrm{R}^{2}(=0.7)$ was found between each year $\mathrm{PCI}_{\text {Annual }}$ and each year rainy days. In the same year of span or decadal 7 times, annual PCI came under the SIPD category. Similarly, during 2012-2018 (seven years), $\mathrm{R}^{2}$ (at $\mathrm{P}=0.05$ ) between each year number of rainy days and $\mathrm{PCI}_{\text {Annual }}$, $\mathrm{PCI}_{\text {Pre-monsoon, }}$ $\mathrm{PCI}_{\text {Monsoon, }}$ and $\mathrm{PCI}_{\text {Post-monsoon }}$ were $0.6,0.6,0.7$ and 0.6 , respectively. From 2012 to 2018, five times $\mathrm{PCI}_{\text {Annual }}$ came under the SIPD class, while four times winter PCI came under the MPD class. Rainfall is a key constituent of the water cycle in nature and a major source of all surfaces and groundwater on land; therefore, analysis of rainfall behaviour of any region has scientific/theoretical and practical/observed value. In this context, the present analysis has variously described rainfall behaviour (concentration/ destitution) as an index of rainfall variability, rainfall erosivity and water availability. Bathinda semi-urban (because AWS represent or is under agricultural domain area) area has been expecting, on $\mathrm{PCI}_{\text {Annual }}$ basis, the biting effects of flooding and erosion. Even when neighbouring districts are not existed under heavy rainfall or flood condition, based on the result above, annual rainfall in Bathinda is highly asymmetrical behaviour and can be classified as SIPD in most of the years (or 22 out of 37 years) and IPD in others (14 times out of 37 years). This fact indicates the inclination of rain towards the high and intensive in the study area but for a short time duration.

Rainfall of such amount has the maximum potential to produce flood conditions, leading to water-related issues and soil erosion/loss problems in the study area. Such rainfall variability can modify the fluvial regime because most of the rainfall is converted into runoff rather than a long infiltration process. Li et al. (2019) have analysed 57 rainfall data using PCI and found that there is an irregularity in rainfall and the reason for that are geographical factors (latitude, longitude, and altitude). Milan et al. (2016) analysed long term data of rainfall (1946-2012) of Serbia using PCI and concluded that PCI help to determine rainfall distribution. Tolika (2019) has analysed the precipitation concentration over Greece on an annual and seasonal basis and concluded that the change could be partially related to the changes in atmospheric circulation over the country on an annual basis. Coscarelli and Caloiero (2012) found that the higher the PCI values are, the greater seasonality of the precipitation distribution is throughout the year. Bartolini et al. (2017) for Italy (Tuscany) and de Luis et al. (2011) for Spain indicate that a 
more irregular precipitation distribution is a more extended phenomenon all over the Mediterranean region. Ziv et al. (2013) analysed the spring precipitation and found that it is decreasing over Israel. Saha (2020) used PCI to evaluate rainfall distribution in Barishal, Bangladesh and found the dominance of strong irregular precipitation distribution in winter rainfall. Valli et al. (2013) applied the PCI method for rainfall analysis of Karimnagar and Prakasam and found that district Prakasam showed highly erratic behaviour of rainfall. Alemu \& Bawoke (2020) used precipitation concentration index (PCI) and seasonality index (SI) for Ethiopia and found a strong irregular rainfall distribution.

\section{Conclusion}

This study has attempted to examine the rainfall variability (1982-2018) behaviour using PCI. The analysis was performed at an annual and seasonal scale (winter, premonsoon, monsoon and post-monsoon). The mean $\mathrm{PCI}_{\text {Annual }}$ value was found at $23.22, \mathrm{PCI}_{\text {monsoon }}$ is 12.46 , and the average decadal PCI is 25.16 (2012-2018) of the 37 years. The Strong Irregularity of Precipitation Distribution (SIPD) was observed for annual and decadal PCI. The analysis results revealed that PCI is an important tool for water resource planning and management, disaster preparedness and provides vital information on water variability for the relevant user agencies. If the rainfall occurs in a very short time or extreme prolonged dry periods may have significant impacts on agriculture, urban and rural flood, and groundwater-dependent ecosystems. Hence, the results of the present work can serve as a planning tool for different stalk holders. The implications of such observed change strongly influence the natural process of groundwater recharge, soil erosion, and flooding. Therefore, it is recommended that the Bathinda Development Authority (BDA) take cognisance of this analysis in planning the new layouts and redevelopment of the old areas of the town in the context of drinking water and flood. PCI can be used as a warning tool and indicator for flooding and erosion. This work suggests that PCI is an important component of natural resource management, risk prediction, and water resource planning. The Global General Circulation Model (GCM) recent CMIP6 scenarios rainfall can be analysed using PCI to study the potential changes of the precipitation and its impacts.

\section{References}

Adegun O, Balogun I, Adeaga O (2012) Precipitation Concentration Changes in Owerri and Enugu. Hydrology for Disaster Management, special publication of NAHS.

Alemu, M. M., \& Bawoke, G. T. (2020). Analysis of spatial variability and temporal trends of rainfall in Amhara region, Ethiopia. Journal of Water and Climate Change, 11(4), 15051520.

Apaydin H, Erpul G, Bayramin I, Gabriels D (2006) Evaluation of Indices fo characterising the distribution and concentration of precipitation: A case for the region of south eastern Anatolia Project, Turkey. J Hydrol 328: 726-732.

Banda, V. D., Dzwairo, R. B., Singh, S. K., \& Kanyerere, T. (2021). Trend analysis of selected hydro-meteorological variables for the Rietspruit sub-basin, South Africa. Journal of Water and Climate Change. https://doi.org/10.2166/wcc.2021.260

Bartolini, G., Grifoni, D., Magno, R., Torrigiani, T., \& Gozzini, B. (2018). Changes in temporal distribution of precipitation in a Mediterranean area (Tuscany, Italy) 1955-2013. International Journal of Climatology, 38(3), 1366-1374.
Coscarelli, R. A., \& Caloiero, T. (2012). Analysis of daily and monthly rainfall concentration in Southern Italy (Calabria region). Journal of Hydrology, 416, 145-156.

De-Luis M, Gonzales-Hudalgo JC, Brunette M, Longares LA (2011) Precipitation Concentration Changes in Spain 1946-2005. Natural Hazards and Earth Systems Sciences 11: 1259-1265.

Du, H., Wang, Y., Wang, Z., Liu, K., \& Cheng, L. (2020). Spatial and temporal characteristics of the daily precipitation concentration index over China from 1979 to 2015. Hydrology Research, 51 (3), 562-582.

Ezemonye MN, Emeribe CN (2011) Correlogram Analysis of Trend and Cycles in Rainfall over Southeastern Nigeria. Pakistan Journal of Social Sciences 8: 325-333.

Gajbhiye, S., Meshram, C., Singh, S. K., Srivastava, P. K., \& Islam, T. (2016). Precipitation trend analysis of Sindh River basin, India, from 102区year record (1901-2002). Atmospheric Science Letters, 17(1), 71-77.

Hernando D, Romana MG (2015) Estimating the Rainfall Erosivity Factor from Monthly Precipitation Data in the Madrid Region (Spain). J HydrolHydromech 63: 55-62.

Iskander SM, Rajib MA, Rahman MM (2014) Trending Regional Precipitation Distribution and Intensity: Use of Climatic Indices. Atmospheric and Climate Sciences 4: 385-393.

Kumbuyo CP, Yasuda H, Kitamura Y, Shimizu K (2014) Fluctuation of Rainfall Time Series in Malawi: An Analysis of Selected Areas. Geofizika 31.

Li, C., Zhang, H., Singh, V. P., Fan, J., Wei, X., Yang, J., \& Wei, X. (2020). Investigating variations of precipitation concentration in the transitional zone between Qinling Mountains and Loess Plateau in China: Implications for regional impacts of $\mathrm{AO}$ and WPSH. Plos one, 15(11), e0238709.

Luis, M. D., Gonzalez-Hidalgo, J. C., Brunetti, M., \& Longares, L. A. (2011). Precipitation concentration changes in Spain 19462005. Natural Hazards and Earth System Sciences, 11(5), 12591265.

Mahato, L. L., Kumar, M., Suryavanshi, S., Singh, S. K., \& Lal, D. (2021). Statistical investigation of long-term meteorological data to understand the variability in climate: a case study of Jharkhand, India. Environment, Development and Sustainability, 1-22.

McGuire B, Macon I, Kilburn C (2002) Natural Hazards and Environmental Change. Arnold, London, 13-61.

Meshram, S. G., Singh, S. K., Meshram, C., Deo, R. C., \& Ambade, B. (2018). Statistical evaluation of rainfall time series in concurrence with agriculture and water resources of Ken River basin, Central India (1901-2010). Theoretical and applied climatology, 134(3), 1231-1243.

Mishra, A.K. 2016. Monitoring Tamil Nadu flood of 2015 using satellite remote sensing Natural Hazards, 82 (2), 1431-1434. https://doi.org/10.1007/s11069-016-2249-5

Nzoiwu PC (2015) An Preliminary assessment of the Effects of Climate Variability and Climate change on Agulu Lake, Anambra State. Unpublished MSc Thesis, The University of Ibadan, Oyo State.

Odjugo PA (2010a) General Overview of Climate Change Impacts in Nigeria. J Hum Ecol 29: 47-55.

Odjugo PA (2010b) Regional evidence of climate change in Nigeria. Journal of Geography and Regional Planning 3: 142-150.

Oliver JE (1980) Monthly Precipitation Distribution: A Comparative Index. Professional Geographer 32: 300-309.

Rawat, K. S., Mishra, A. K., Singh, S. K., Kumar, S., \& Bahuguna, A. (2018) Rainfall trend analysis using non parametric test and Satellite data of Pauri Garhwal District of Uttarakhand, India. 11(9): 1098-1107

Saha S. (2020). Precipitation concentration index (PCI) a tool to evaluate the distribution of Rainfall, Barishal, Bangladesh. International Journal of Advanced Geosciences, 8(2). 193-1996.

Tolika, K. (2019). On the analysis of the temporal precipitation distribution over Greece using the Precipitation Concentration Index (PCI): annual, seasonal, 
monthly analysis and association with the atmospheric circulation. Theoretical and Applied Climatology, 137(3), 23032319.

Valli M, Sree KS, Krishna IVM (2013) Analysis of Precipitation Concentration Index and Rainfall Prediction in various Agro Climate Zones of Andhra Pradesh, India. Inter Research Journal EnvSci 2: 53-61.

Zhang, K., Yao, Y., Qian, X., \& Wang, J. (2019). Various characteristics of precipitation concentration index and its cause analysis in China between 1960 and 2016. International Journal of Climatology, 39(12), 4648-4658.

Ziv, B., Saaroni, H., Pargament, R., Harpaz, T., \& Alpert, P. (2014). Trends in rainfall regime over Israel, 1975-2010, and their relationship to large-scale variability. Regional Environmental Change, 14(5), 1751-1764. 